As belas-artes reduzidas a um mesmo princípio. Charles Batteux (São Paulo: Humanitas \& Imprensa Oficial, 2009)

\title{
O PRINCÍPIO PRIMEIRO
}

As doutrinas artísticas antigas, refundadas em algum neoaristotelismo, assim como em obras poéticas também pertencentes à antiguidade, a aristotélica e a horaciana, principalmente, serviram à composição do ensaio intitulado As belas artes reduzidas a um mesmo princípio, de Charles Batteux, professor de retórica, filosofia e de poesia grega e latina no Collège Royal de Paris, em fins do século XVIII. Sucedem o Les beaux-arts outras obras fundamentais escritas por Batteux ao longo do tempo em que desempenhou as referidas funções, de professor e reitor, tais como o volumoso Cours de Belles-Lettres ou Principes de la Littérature, de 1753, ou o Les Quatre Poétiques, d'Aristote, d'Horace, de Vida, de Despreáux, avec les traductions \& des remarques, de 1771, Histoire des Causes Premières, de 1769 , além de outros. Não se trata aquele, no entanto, de um tratado de execução para as artes nem tampouco pode ser proposto como obra precursora quanto à emergência de estéticas que fundamentam o fazer artístico segundo a noção de vida subjetiva do artista, principal critério, conforme aquelas, para o desenvolvimento das artes na chave do progresso e do devir. Convertido ao conceito de "princípio unificador", das artes, o princípio a que se refere o título da obra não é redutor quanto à implicação das técnicas e dos modelos de imitação, essencializando-os, ao mesmo tempo em que se amplifica a atuação da subjetividade e da individualidade como principais móveis da criação poética e artística. Não pertence, caso se queira dizer de outro modo, à Estética ou à Filosofia da Arte, mas às doutrinas poético-retóricas que pensam as artes, em termos de comparação, paragone, na chave da imitação e do decoro, conforme, preceito aristotélico. Confirma-o a própria exposição feita por Batteux no prólogo do As belas-artes: "Após tantas buscas inúteis e não ousando entrar sozinho em uma matéria que, vista de perto, parecia tão obscura, atrevia-me a abrir Aristóteles, do qual eu havia escutado exaltarem a Poética. [...] A máxima de Horácio se achou verificada pelo exame: ut pictura poesis. Constatou-se que a poesia era em tudo uma imitação, assim como a pintura. Eu ia mais longe: tentava aplicar o mesmo princípio à música e à arte do gesto, e espantou-me a justeza com a qual lhes convinha. Foi is- 
so que produziu esta pequena obra, onde se pressente que a poesia deve ocupar a posição principal, tanto por causa de sua dignidade, quanto por ter sido sua ocasião." Ao invocar o kairos, a ocasião, ou "o momento oportuno", para a poesia, Batteux subordina a imitação operante em todas as artes àquela produzida pela poesia, construindo o seu discurso mediante outros princípios, embora não declarados no ensaio, advindos da retórica aristotélica. Apta menos a persuadir do que a desenvolver os meios exigidos para cada caso, com vistas à persuasão, esta retórica provê para Batteux as provas inartísticas, fornecidas pelas leituras de Aristóteles, Horácio, e de outros, assim como as artísticas, com as quais o autor informa o leitor sobre a motivação do ensaio, para o esclarecimento de suas ideias sobre as belas-artes e a poesia, ou para prestação de contas a si mesmo, conforme o que ele relata, encontrada por método ou inventada por cogitação própria. De acordo com o mesmo, a natureza fornece o melhor modelo a ser imitado para quem saiba imitála bem, quer dizer, convenientemente, sendo, por outro lado, um despropósito imitá-la "servilmente", tal como ela é. O conveniente é o bom que, por sua vez, é "digno de ser escolhido em si e por si”, segundo Aristóteles, ou aquilo que, "pela sua presença, outorga bem-estar e autossuficiência, [...] ou o que produz e conserva esses bens" (Retórica, I,6). O bom é belo, e é útil, sendo conveniente, por exemplo, que o "mais fácil seja maior que o mais difícil" porquanto sendo em geral "o mais difícil maior que o mais fácil", todavia, é a este último que sempre desejamos. Reduzir as artes a um mesmo princípio implica simplificar as regras, tendendo-se à conveniência do "mais fácil" ou do mais simples, uma vez que o modelo a ser imitado por todas as artes é sempre o mesmo, ou seja, a natureza, em si, bela, boa e útil. Para Batteux o "juiz nato de todas as belas-artes é o gosto", uma vez que o bom gosto nas artes, a par da imitação da bela natureza, é regrado pelo sentimento, ou pelo "gênio", sendo este o sentimento em conformidade com as coisas naturais. O gosto é para as artes o que a inteligência é para as ciências, estas interessadas pelo verdadeiro, aquelas, pelo que é belo e bom, enquanto expressão do verossímil. "Agradar", "levar ao prazer", sempre foi o seu objeto, constituindo-se as artes os seus "novos objetos", embora o gosto sempre permaneça constantemente o mesmo, uma vez que procede da imitação do "modelo da natureza”. Os objetos apresentados pelas artes, segundo Batteux, devem ter "uma relação íntima conosco", despertando o nosso interesse à 
medida que nosso espírito prova da variedade, assim, multiplicando em nós os sentimentos e as ideias. À arte cabe a função de dotar as diferentes partes desses objetos de um "grau requintado de força e de elegância”, fazendo-os parecer como novos, porquanto apresentados de maneira singularíssima, para a audiência ou espectadores, que, por sua vez, compartilham das mesmas doutrinas do "legislador", e julgam o êxito da ficção.

As definições de Batteux sobre "o gosto" coincidem também com as de Montesquieu, que foi incumbido de escrever um verbete sobre este conceito para a Enciclopédia de D’Alembert e Diderot, anotadas em um ensaio inacabado iniciado em 1753. Para Montesquieu, o "gosto é aquilo que nos liga a uma coisa por meio do sentimento". O gosto, adquirido, cultivado, dá a conhecer, para o sentimento, as regras particulares que o "gênio" do artista utilizará na invenção e disposição de seu discurso, comportando-se todas as artes particulares como formas discursivas consoantes à poesia, que é exemplo para Batteux de imitação do belo natural, estendido ao gosto, e, assim, a todas as artes. Sendo o "gênio" uma aptidão e uma disposição do ethos do artista na contrafação do modelo natural, por meio da imitação, o "gosto", para Batteux, consequentemente está subordinado ao mesmo princípio, sendo em relação ao mesmo não uma aptidão produtiva, como o "gênio", mas somente apreciativa e legislativa. O "gênio", por sua vez, é uma tópica que também corresponde às doutrinas, não investido ainda da subjetividade psicologizada que o projetará no "romantismo" como principal expoente de arte que se apresente como expressão autônoma e intimista. Para Batteux, a sua função consiste "não em imaginar o que pode ser, mas encontrar o que é”, inventando, isto é, achando um objeto já existente com o propósito de imitá-lo. Trata-se de uma aptidão apropriada ao exercício, principal, de reconhecimento, feito também pelo "gosto", uma vez que na natureza, onde tudo existe, pode ser encontrado o modelo prototípico para as artes que nunca sobrevêm do nada. Ao servir como meios de transporte dos "traços que estão na natureza e apresentá-los em objetos que não são naturais", as artes assumem a direção da produção do verossímil, e não da busca pelo verdadeiro, servindo-se da matéria que a natureza efetivamente lhe oferece. Tal tópica se apresenta em muitos outros lugares, por exemplo, em Kant, na terceira crítica, obra do final do século XVIII, quando este analisa a relação entre "bela-arte, gênio e gosto". Para Kant, do mesmo modo, a ar- 
te, usando a matéria da natureza, é capaz de criar como uma outra natureza, e em vista disso propõe: "Uma beleza natural é uma bela coisa; a beleza artística é a bela representação de uma coisa" (Crítica do Juízo, 48). Batteux é mais explícito. "O que é uma pintura?", pergunta ele, para em seguida responder: "Uma imitação dos objetos visíveis. Ela nada tem de real, nada tem de verdadeiro. Tudo nela é aparência, e sua perfeição só depende de sua verossimilhança com a realidade."

Divergem os dois autores, sutilmente, quanto à direção determinada para o conceito de "gênio", aptidão natural para ambos, porém, voltada mais à invenção de "ideias estéticas" ou daquelas "ricas em imaginação", segundo Kant, do que algo que se apresenta como uma acurada capacidade investigativa, segundo o autor francês. Talvez possa se propor, aqui, a captura do conceito de "gênio" pela filosofia do final do século XVIII, pelo que Kant o determina como a "disposição natural inata" ativa no sujeito, enquanto natureza reflexionante, de onde provém toda regra necessária à produção da bela-arte, dispensando outras regras que lhe sejam alheias. Contingentes, as leituras que se fizeram, sobretudo no século XIX e início do século XX, destas e de outras proposições kantianas, serviram às definições mais recentes de arte para as quais a expressão e a criação, principais chaves de entendimento destas, rondam subterraneamente o autor subjetivo. Batteux, porém, deve ser lido ainda em concordância com as doutrinas neoaristotélicas circulantes à época. Para estas, as artes pertencem ao Intelecto Ativo que é parte da Razão Universal, conduzindo-se como hábitos factivos ou conforme uma recta ratio factibilium, "a reta razão dos factíveis", sendo o gênio uma aptidão que imita, emula e aperfeiçoa, pelo composto imitado, o modelo da natureza, sem deixar o referido composto "de ser natural". É, ao lado do "gosto", o "gênio", um dos critérios da produção artística, não determinante, mas imitativo, por isso condutor quanto à natureza das artes e seus pressupostos, retóricos, de decoro e elegância. Em outras palavras, o "gênio" escolhe e organiza entre os inúmeros objetos naturais, aqueles que são convenientes à invenção e à imitação, na composição das partes da arte à qual o artista se dedica. Por isso, Batteux afirma: "O gênio é como a terra que não produz nada de que não tenha recebido a semente." Servindo-lhe de apoio e alimento, a natureza dispõe a ele as suas riquezas, encarecendo a imitação como operação de reconhecimento destas, "naquilo que é propriamente arte", ou 
como construção de um "fundo de verdade," misturada habilmente à ilusão. Lendo Aristóteles, possivelmente a partir da edição comentada da Poética, publicada por André Dacier, em 1692, Batteux redita a comparação entre poesia e história, esta ligada ao verdadeiro, aquela, ao verossímil: "O historiador dá os exemplos tais como são, frequentemente imperfeitos. $\mathrm{O}$ poeta os dá tais como deveriam ser. E é por isso que, segundo o mesmo filósofo, a poesia é uma lição muito mais instrutiva do que a história." A imitação prevê a seleção das partes da natureza e também dos fatos assim ditos verdadeiros na efetuação de uma ficção baseada no verdadeiro, vera fictio, associada à composição do pleno artifício, falsa fictio, operação também retórica que, para o autor, é exemplificada pela tópica "inscrição de similitudes". Operante em Plínio o Velho, que é referência para Batteux e todos os outros autores do período, esta tópica é reapresentada pelo nosso autor no exemplo da seleção de belezas, feita por Zêuxis para a pintura de uma deusa, ou pela pintura das batalhas de Alexandre, por Le Brun, ou ainda nas Musas de Hesíodo, etc.

A imitação, contudo, somente se completa como perfeição de arte, se o estado do gênio, excitando-se, no momento em que se completa a composição, preenche-o como se fosse uma "ideia viva", que o faz se esquecer de si mesmo. Extasiado, o gênio tem, na chave do entusiasmo platônico, redito por Cícero, condições de se unir ao seu objeto, vivendo pelo sentimento os artistas os personagens de suas invençôes, "colocando-se no meio das coisas que queiram representar", transportando-se, por exemplo, os pintores, para as cenas de batalha que desejam pintar. Para Batteux, as artes consistem na imitação da bela natureza, que em si é boa e útil, "representada", assim, "ao espírito no entusiasmo". Divididas em três espécies, as "artes mecânicas", as "belas-artes", e as da "eloquência e arquitetura", são as de segunda espécie a receber tratamento que as articula em torno do princípio de imitação poética. Assim, logo após tratar da natureza do gênio e do gosto, Batteux lança-se a analisar a operação do "mesmo princípio" à poesia, suas divisões e gêneros, "à pintura, à música e à dança”. Homólogas à poesia, estas artes estão destinadas a se mostrarem juntas ou reunidas, principalmente a primeira, seguida das duas últimas, porquanto a elas cabe a tarefa de "apresentar a imagem das açôes e paixões humanas", aristotelicamente. Uma vez que a natureza criou os seus princípios, com o fim de mantê-los unidos, este é o princípio fundamental ou 
o primeiro princípio. À arquitetura, escultura e pintura, por outro lado, caberia a missão de armar a cena para o espetáculo ou para a exposição do composto imitado. Para tanto, Batteux propõe para esta última, a pintura, também uma homologia com a poesia, extensível às demais artes. Basta, segundo ele, que se substituam os nomes "poesia, fábula, versificação" pelos nomes "pintura, desenho, colorido". Vistos hierarquicamente como partes da pintura, "desenho e colorido", neste último incluso o claro-escuro, são remissivos à divisão da pintura que circula pelos tratados a ela dirigidos desde pelo menos meados do século XV. Pense-se, por exemplo, na articulação "desenho/claro-escuro/cor", operante em Alberti, depois vigente nas academias de Bologna, Roma e França, e alhures. Articulação que também se instalará mais tarde na Instituição acadêmica brasileira, do século XIX, à luz de reflexão quase sempre estatutária, legível em decretos de nossa burocracia oficial.

\author{
Luiz Armando Bagolin \\ (Instituto de Estudos Brasileiros /USP)
}

